
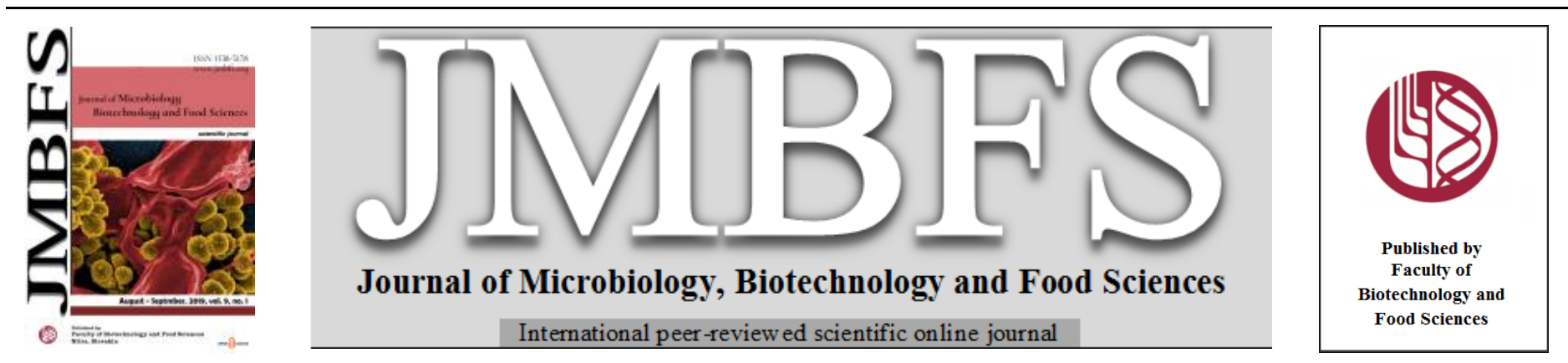

\title{
EFFECT OF BIOSYNTHESIZED COPPER NANOPARTICLES (CUNPS) ON THE GROWTH AND BIOFILM FORMATION OF FLUCONAZOLE-RESISTANT CANDIDA ALBICANS
}

\author{
Ubaid Rasool, Saroj Kumar Sah and S. Hemalatha* \\ Address(es): S. Hemalatha \\ School of Life Sciences, BSA Crescent Institute of Science and Technology, Chennai, India-600048.
}

*Corresponding author: hemalatha.sls@crescent.education

doi: 10.15414/jmbfs.2019.9.1.21-24

\begin{abstract}
ARTICLE INFO
Received 16.3. 2018

Revised 21. 2. 2019

Accepted 21. 2. 2019

Published 1. 8. 2019

Short communication

open $\mathcal{O}$ access

ABSTRACT

Biosynthesized copper nanoparticles through extracellular method were employed in this study to evaluate their effect on fluconazoleresistant $C$. albicans. MIC and MBC of CuNPs against $C$. albicans was $2.5 \mathrm{mg} / \mathrm{ml}$ and $5 \mathrm{mg} / \mathrm{ml}$ respectively, giving a tolerance level of 2. This was followed by absorbance measurements $\left(\mathrm{OD}_{600}\right)$ to further confirm the growth inhibiting effect of CuNPs in liquid culture. Furthermore, the well-plate method was performed to check the antifungal activity of two different concentrations of CuNPs $(5 \mathrm{mg} / \mathrm{ml}$ and $10 \mathrm{mg} / \mathrm{ml})$ against $C$. albicans by observing the zones of inhibition and fluconazole $(25 \mu \mathrm{g} / \mathrm{ml})$ was used as a control. Static biofilm assay was performed to check whether the CuNPs were able to inhibit the formation of biofilm by $C$. albicans which was further analyzed through spectrophotometric measurements. Growth curve analysis showed the inhibitory effect of CuNPs on C. albicans at different time intervals. The results from the current investigation suggested that the CuNPs were effective in controlling the fluconazole-resistant $C$. albicans and can be utilized as alternative antifungal agents.
\end{abstract}

Keywords: CuNPs, resistant, growth inhibition, biofilm, growth curve

\section{INTRODUCTION}

Antibiotic resistance is a worldwide issue which poses a threat to clinical practice, particularly in hospitals. This complication is further exaggerated by the less availability of new antibiotics (Boucher $\boldsymbol{e t}$ al., 2009). Research on finding some novel, harmless and effective therapeutic drugs that can replace the less effective antibiotics can be a means of controlling this menace of antibiotic resistance (Jones et al., 2004; Nagajyoti et al., 2011). More complications in human clinical practice arise due to the undesirable spread of fungal infections originating as a result of uncommon and unexpected species of Candida, which is furthermore intensified by an increase in the number of immunocompromised patients, posing a threat in human clinical practice. The frequency with which fungal infections are spreading has been specified as a result of certain risk factors including the immunological condition of the host, application of broadspectrum antibiotics, transplants, continued use of intravascular and urethral catheters, use of corticosteroids and parenteral nutrition (Francois et al., 2013) Candida albicans is generally believed to be the most pathogenic Candida species and so far, this species remains the most persistent Candida species that is isolated clinically (Borman et al., 2016). Candida albicans has a major role in causing candidemia. The other species of Candida including C. krusei, C. glabrata, C. tropicalis and C. parapsilosis also play a role in causing candidemia (Silva et al., 2012). The ability of Candida species to thrive on human mucous membranes, which is due to different virulence factors including the transition between yeast and hyphae, defensive ability against the host immune system, adhesion, biofilm-forming capability on host tissues or on medical devices and production of extremely harmful enzymes such as hydrolytic proteases, phospholipases and hemolysin, resulting in the development of various diseases ranging from mucocutaneous overgrowth to diffused infections (Deorukhkar $\boldsymbol{e t}$ al., 2014). The objective of this study was to evaluate the effect of CuNPs on the growth and biofilm of fluconazole-resistant $C$. albicans.

\section{MATERIAL AND METHODS}

\section{Fungal strain and copper nanoparticles}

The fungal strain (clinical isolate) i.e. Candida albicans used in this study was obtained from Tagore Medical College, Chennai, India after proper approval from institutional ethics committee (BSAU: REG-OFF: 2016/02SLS). The CuNPs synthesized in our previous study were used to evaluate the antifungal effects on Candida albicans. The synthesis of CuNPs was performed through a biological method via the assistance of a marine actinomycetes isolated from a seaweed (Gelidium sp.). CuNPs were synthesized through an extracellular method utilizing the cell-free extract obtained after culturing the actinomycetes in liquid media. $100 \mathrm{mM} \mathrm{CuSO} 4$ was mixed with an equal volume of the extract resulting in the synthesis of CuNPs. Freshly synthesized CuNPs were characterized through UV-Vis spectroscopy, FTIR analysis, SEM, EDAX and TEM and were further assayed for their antibacterial potential against 5 different human pathogenic bacteria (Rasool \& Hemalatha, 2017).

\section{Media preparation, autoclaving and inoculation}

All the media preparations were carried out using analytical grade chemicals. LB broth (supplemented with sucrose for proper growth of Candida albicans) and Luria-Bertani agar (LBA) were used as liquid and solid media respectively in order to grow Candida albicans and to perform the experiments. The isolate was continuously sub-cultured and maintained as a slant.

Before performing any experiments, all glassware and media were properly autoclaved at $121^{\circ} \mathrm{C}$ for $15 \mathrm{~min}$ to eliminate any sort of contamination.

\section{Minimum inhibitory concentration (MIC) and Minimum fungicidal concentration (MFC)}

Serial micro-dilution and surface drop method were employed to evaluate the minimum inhibitory concentration (MIC) and minimum fungicidal concentration (MFC) of CuNPs respectively (Dash $\boldsymbol{e t}$ al., 2012). MIC was performed in a 96well microplate where CuNPs were serially diluted with LB broth to prepare various concentrations $(5 \mathrm{mg} / \mathrm{ml}, 2.5 \mathrm{mg} / \mathrm{ml}, 1.25 \mathrm{mg} / \mathrm{ml}, 0.625 \mathrm{mg} / \mathrm{ml}$ and $0.3125 \mathrm{mg} / \mathrm{ml}$ ). MIC was performed in triplicates. The $10 \mu 1$ fresh culture of Candida albicans was added to each well. A positive (Candida albicans $+\mathrm{LB}$ broth) and a negative control (LB broth alone) were used. Fluconazole $(25 \mu \mathrm{g} / \mathrm{ml})$ was used as an antibiotic control. After performing the MIC experiment, 96-well microplate was incubated at $37^{\circ} \mathrm{C}$ and was visually observed after a period of 24 h.

Surface drop method was employed to determine the Minimum fungicidal concentration (MFC) of CuNPs. $10 \mu \mathrm{l}$ aliquots from all the MIC dilutions were inoculated as a drop at eight different points on sterile LBA plates. The plates were incubated at $37^{\circ} \mathrm{C}$ for $24 \mathrm{~h}$. This experiment was performed in triplicates. 
The 96-well microplate used to determine the MIC of CuNPs was subjected to spectrophotometric measurements $\left(\mathrm{OD}_{600}\right)$ to further confirm the antifungal activity of CuNPs.

Antibiotic susceptibility testing and antifungal activity of CuNPs through the well-plate method

To check whether the isolate used in the study is resistant to fluconazole $(25 \mu \mathrm{g})$, an antifungal disc of antibiotic (fluconazole, $25 \mu \mathrm{g} / \mathrm{ml}$ ) was placed on a solid agar plate seeded with an overnight culture (OD adjusted to $0.5 \mathrm{McFarland}$ standard) of Candida albicans. The plate was incubated at $37^{\circ} \mathrm{C}$ for $24 \mathrm{~h}$ and was later visually observed for the zone of inhibition (Ekwealor et al., 2016).

The antifungal activity of CuNPs against Candida albicans was carried out through the well-plate method (Kaur et al., 2016). Candida albicans was freshly cultured in a test-tube using Luria-Bertani broth as a medium of inoculation and seeded on LB agar plates. After proper absorption of fungal culture on the plate, proper wells were cut and loaded with $5 \mathrm{mg} / \mathrm{ml}$ and $10 \mathrm{mg} / \mathrm{ml}$ of CuNPs. $\mathrm{CuSO}_{4}$ solution was used as a negative control. $25 \mu \mathrm{g} / \mathrm{ml} \mathrm{disc} \mathrm{of} \mathrm{fluconazole} \mathrm{was} \mathrm{used} \mathrm{as}$ a positive control. The plates were incubated at $37^{\circ} \mathrm{C}$ for $24 \mathrm{~h}$ and were observed for the zones of inhibition.

\section{Static biofilm assay}

This experiment was performed to check the biofilm inhibition potential of CuNPs by following a method as described by Reshamwala and Noronha (2011) with slight modifications. Briefly, an overnight culture of $C$. albicans was diluted in fresh LB broth and adjusted to 0.5 McFarland standard using borosilicate glass tubes $(70 \times 10 \mathrm{~mm})$. C. albicans was treated with the concentration corresponding to MIC of CuNPs. A culture without treatment was used as a positive control, culture treated with fluconazole $(25 \mu \mathrm{g})$ was used as a negative control and LB broth alone was used as a blank. After performing the experiment, the tubes were incubated at $37^{\circ} \mathrm{C}$ for $18-24 \mathrm{~h}$. The detection of a static biofilm was carried out by discarding the LB medium and washing the tubes twice with double distilled water. This was followed by the addition of $0.1 \%$ crystal violet. The tubes were allowed to stand for $15 \mathrm{~min}$. After properly washing out the dye with double distilled water, the appearance of the violet ring in the tubes demonstrated the presence of biofilm. This was followed by spectrophotometric measurements after the addition of $30 \%$ glacial acetic acid to all the tubes in order to quantify the biofilm.

\section{Growth curve study}

C. albicans was allowed to grow in LB broth till it reached to its log phase. Later, a fresh LB broth was prepared and the grown $C$. albicans was added so that an optical density of 0.1 was attained. A solution of CuNPs was prepared (MIC concentration) which was added to the culture medium. The culture was incubated at $37^{\circ} \mathrm{C}$ in an incubator shaker at $200 \mathrm{rpm}$. Growth rate and the concentration of $C$. albicans was determined by measuring OD at $600 \mathrm{~nm}$ at 5 different time intervals and the growth curve was analyzed (Maiti et al., 2014).

\section{RESULTS AND DISCUSSION}

\section{MIC and MFC determination}

Minimum inhibitory concentration (MIC) of biosynthesized CuNPs against Candida albicans was carried out in a 96-well microplate. MIC value was found to be $2.5 \mathrm{mg} / \mathrm{ml}$. MIC was taken as the concentration of CuNPs where there was no visible growth. Following MIC, minimum fungicidal concentration (MFC) of CuNPs against Candida albicans was carried out and it was observed that 5 $\mathrm{mg} / \mathrm{ml}$ of CuNPs completely inhibited the growth of Candida albicans. All other concentrations were least effective with more or less growing $C$. albicans. Here, MFC value was the exact double of MIC value.

After MIC and MFC were calculated, the 96-well microplate was analyzed via spectrophotometric measurements to calculate $\mathrm{OD}_{600}$ to get a clear picture of the growth inhibition of Candida albicans by CuNPs. Results are shown in figure 1. It was observed that with a decrease in the concentration of CuNPs, the OD values increased parallelly. $5 \mathrm{mg} / \mathrm{ml}$ of CuNPs was the most effective followed by other concentrations and $0.3125 \mathrm{mg} / \mathrm{ml}$ of CuNPs was the least effective. The antifungal properties of CuNPs against $C$. albicans have been reported in various other studies, even though the MIC values reported in our study differ from those studies (Amiri et al., 2016; Usman et al., 2013; Soltani et al., 2017). There are various reasons that lead to the difference in the activities such as the size of the nanoparticles which is an important factor. It is generally known that the size and shape of nanoparticles have an influence on their chemical, optical and thermal properties. So, the size and other characteristics of the nanoparticles can be the reason for variable antimicrobial properties (Akther et.al., 2018).The stabilizing agent used in the synthesis of nanoparticles can also have an effect on the properties of nanoparticles (Vazquez-Munoz et al., 2014). The effect of nanoparticles is also species dependent (Yoon et al., 2007). In our study, CuNPs which were originally synthesized via the assistance of a marine actinomycetes, had a growth inhibiting effect on $C$. albicans where $5 \mathrm{mg} / \mathrm{ml}$ of CuNPs proved more effective and $0.3125 \mathrm{mg} / \mathrm{ml}$ proved least effective. Still, the least effective concentration of CuNPs $(0.3125 \mathrm{mg} / \mathrm{ml})$ was able to inhibit the growth of $C$. albicans more effectively compared to the control (untreated) as shown in figure 1 .

A ratio of $\mathrm{MFC} / \mathrm{MIC}$ was also calculated to get an idea about the fungicidal (MFC/MIC $<4)$ or fungistatic effect $(\mathrm{MFC} / \mathrm{MIC} \geq 4)$ of CuNPs on $C$. albicans (de Castro et al., 2015). The ratio of MFC/MIC was calculated as 2 which means that CuNPs had a fungicidal effect on $C$. albicans.

Table 1 MIC and MBC values of CuNPs against $C$. albicans

\begin{tabular}{|l|l|l|l|}
\hline Strain & MIC $(\mathbf{m g} / \mathbf{m l})$ & MBC $(\mathbf{m g} / \mathbf{m l})$ & MFC/MIC \\
\hline Candida albicans & 2.5 & 5 & 2 \\
\hline
\end{tabular}

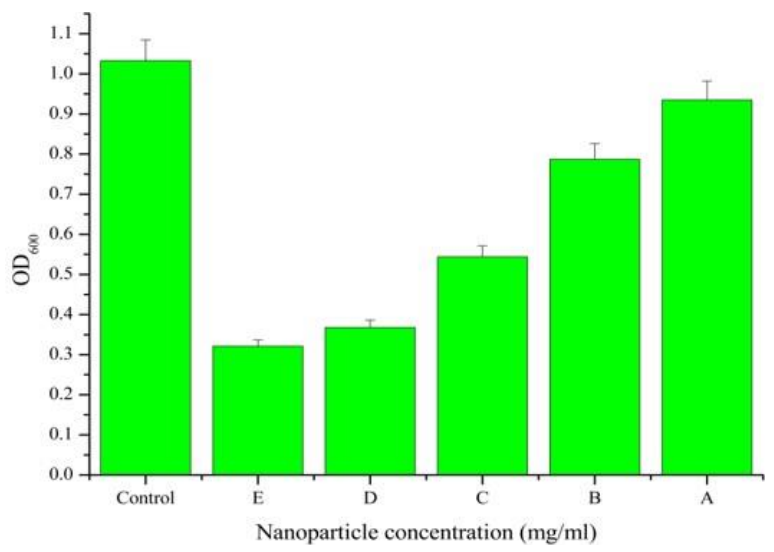

Figure 1 Graphical representation of $\mathrm{OD}_{600}$ (From A to $\mathrm{E}$, the concentration of CuNPs increases from $0.3125 \mathrm{mg} / \mathrm{ml}$ to $5 \mathrm{mg} / \mathrm{ml}$. The graph represents an increase in the spectroscopic measurements as the concentration of CuNPs decreases)

Antibiotic susceptibility and antifungal activity through the well-plate method

Susceptibility testing revealed that $C$. albicans used in this particular study was resistant to $25 \mu \mathrm{g} / \mathrm{ml}$ of fluconazole which is a standard concentration of this antibiotic prescribed for any fungal infection caused by $C$. albicans (CLSI, 2017). There was no zone formation with the antibiotic disc used showing the higher resistance of $C$. albicans towards the antibiotic. Antifungal activity of CuNPs through well-plate method displayed smaller zones of inhibition where 10 $\mathrm{mg} / \mathrm{ml}$ of CuNPs showed little higher zones $(12.5 \mathrm{~mm})$ compared to $5 \mathrm{mg} / \mathrm{m}$ $(11.5 \mathrm{~mm})$. The reason behind the less activity of CuNPs in solid media couldn't be known which needs to be investigated more. No zones were observed with $\mathrm{CuSO}_{4}$ solution (negative control) as well as the blank. Results of susceptibility and antifungal activity through well-plate method are shown in figure 2.

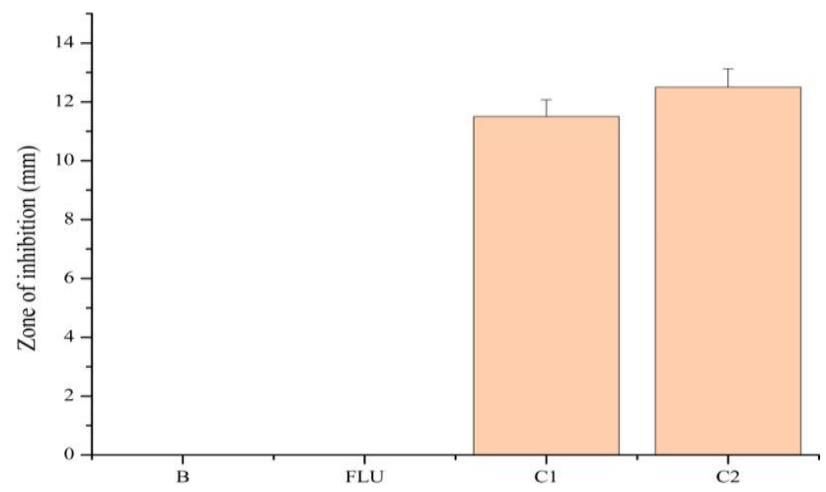

$$
\text { Figure } 2 \mathrm{~b} \text { Treatment }
$$

Figure 2 Graphical representation of zones of inhibition of CuNPs (well-plate method), against Candida albicans $(\mathrm{C} 1=5 \mathrm{mg} / \mathrm{ml}$ and $\mathrm{C} 2=10 \mathrm{mg} / \mathrm{ml}$ of CuNPs, FLU=Fluconazole, $\mathrm{B}=$ Blank $\mathrm{CuSO}_{4}$ )

\section{Biofilm inhibition}

The tube method employed for controlling the biofilm formation in C. albicans was effective. The diagrammatic representation of the biofilm inhibition by CuNPs and graphical representation with spectrophotometric measurements that were carried out after the addition of $30 \%$ glacial acetic acid is presented in 
figure 3. It is evident from both the figures that CuNPs were more effective in controlling the formation of biofilm when compared to fluconazole. Formation of biofilms by $C$. albicans is not a simple gathering of cells, but rather highly structured microbial communities, which is being assumed to carry out different functions such as to ease the process of the influx of nutrients and waste disposal. Most of the researchers agree to the point that the biofilm formation in $C$. albicans comprises of different phases which include initial adherence, colonization, proliferation, maturation and ultimately dispersion so that the process of biofilm formation gets repeated all over again. Biofilm formation by mature $C$. albicans consists of a network of yeasts, hyphae and pseudohyphae which possess a complex three-dimensional structure. (Uppuluri et al., 2009). There are some studies carried out on the inhibition of $C$. albicans biofilms. A study by Bruzual et al., (2007) reported the inhibition of biofilm formation by fluconazole-resistant $C$. albicans by fluconazole itself. They also stated the effect as biofilm-specific rather than the effect of fluconazole. A study by Rahimi $\boldsymbol{e}$ al., (2016) reported the inhibition of $C$. albicans biofilm by copper oxide nanoparticles. They conducted their study on a standard strain of $C$. albicans.

In this study, we found that the biosynthesized CuNPs attenuated the $C$. albicans biofilm formation more effectively compared to the antibiotic fluconazole. A study by Yu et al., (2016) reported that the activity of gold nanoparticles in inhibiting the $C$. albicans biofilm to be associated with the electrostatic interaction between nanoparticles and fungal cells. The biosynthesized CuNPs not only can inhibit the pathogenic bacteria, as demonstrated in our previous study, but can also impair the biofilm formation in $C$. albicans. Inhibition of biofilm formation in pathogenic microbes has received a great interest during recent times (Akther $\boldsymbol{e t} \boldsymbol{a l}$.),As the biofilm formation depends on cell-to-cell signalling facilitated by quorum sensing (QS) molecules, maximum approaches towards biofilm inhibition are targeted towards the signalling system. A single possible mechanism that can be involved here is the strong electrostatic attractions between CuNPs and cell wall surface of $C$. albicans leading to an interruption in the adhesin-mediated interaction between the cells of $C$. albicans and the substrate surfaces.

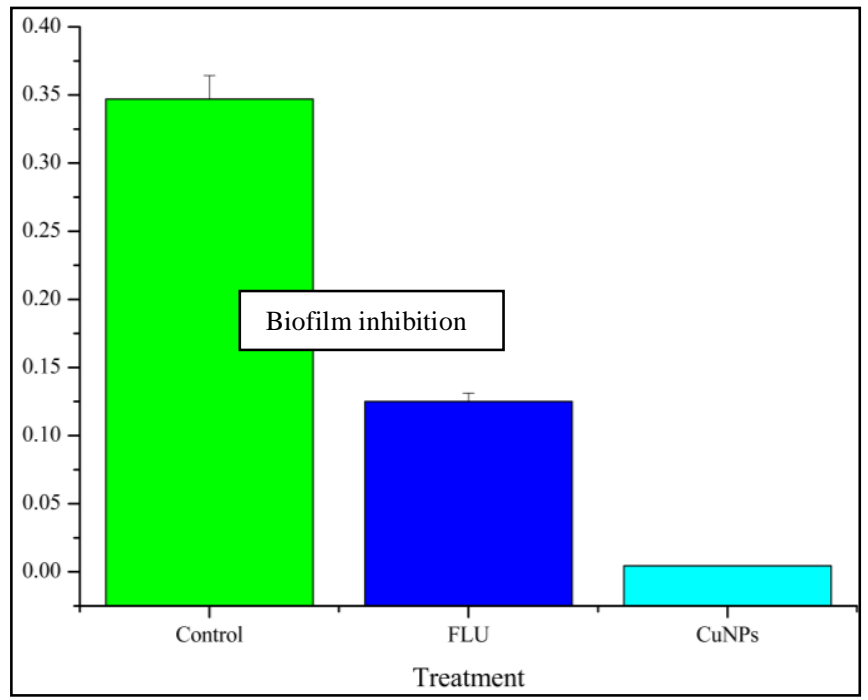

Figure 3 Biofilm inhibition by CuNPs. The above graph displays the inhibition of $C$. albicans biofilm by CuNPs. Compared to fluconazole, CuNPs were more effective in inhibiting the biofilm

\section{Growth curve analysis}

After observing and analyzing the effect of CuNPs on $C$. albicans with time and plotting a graph from the observed data, the slope of the $C$. albicans growth curve decreased with the passing time till a straight line was observed. The initial growth curve of $C$. albicans starting at $0.1 \mathrm{~nm}$ reduced to $0.013 \mathrm{~nm}$ after treatment with CuNPs. Untreated $C$. albicans showed a luxuriant growth with increasing time intervals. Hence, it can be concluded that CuNPs had a timedependent effect on the growth of $C$. albicans.

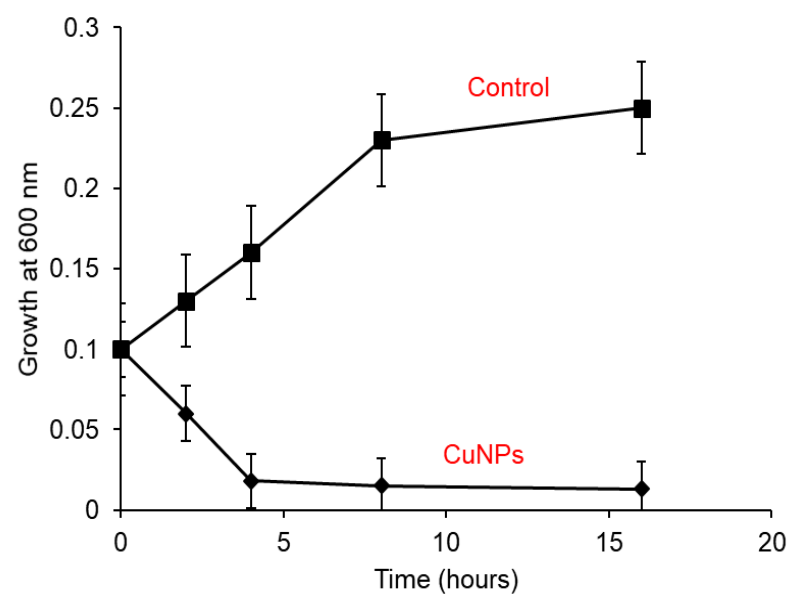

Figure 4 Growth curve with initial OD 0.1. The above graph shows the timedependent effect of CuNPs on the growth of $C$. albicans

\section{CONCLUSION}

This study was carried out to widen the area of biological activities that CuNPs could possess. In this study, CuNPs were effective in controlling the growth in fluconazole-resistant $C$. albicans. After observing and calculating the MIC and $\mathrm{MBC}$ values followed by growth assay, it was concluded that CuNPs were effective in controlling the growth of $C$. albicans in liquid media. However, CuNPs were not much effective in controlling the growth of $C$. albicans in solid media which needs some further investigations. CuNPs were also effective in controlling the formation of biofilm in C. albicans. It can thus be concluded that CuNPs used in this study can be used as disinfectants or can be applied on liquid settings which are infected with $C$. albicans.

Acknowledgements: The authors of this study are very thankful to BSA Crescent Institute of Science and Technology for providing all the necessary facilities to carry out the research. Ubaid Rasool is grateful towards the Institute for providing Junior Research Fellowship (JRF).

\section{REFERENCES}

Boucher, H. W., Talbot, G. H., Bradley, J. S., Edwards, J. E., Gilbert, D., Rice, L. E., Scheld, M., Spellberg, B., \& Bartlett, J. (2009) Bad bugs, no drugs: no ESKAPE! An update from the infectious diseases society of America. Clinical Infectious Diseases, 48(1), 1-12. http://dx.doi.org/10.1086/595011

Jones, M. E., Karlowsky, J. A., Draghi, D. C., Thornsberry, C., Sahm, D. F., \& Bradley, J. S. (2004) Rates of antimicrobial resistance among common bacterial pathogens causing respiratory, blond, urine, and skin and soft tissue infections in pediatric patients. Eur J Clin Microbiol Infec Dis, 23(6), 445-55. http://dx.doi.org/10.1007/s10096-004-1133-5Nagajyoti, P. C., Prasad, T. N. K. V., Sreekanth, T. V. M., \& Lee, K. D. (2011) Bio-Fabrication of silver nanoparticles using leaf extract of Sauruschinenis. Dig J Nanomater Bios, 6(1), 121-133.

François, L. M., Wilson, D., \& Hube, B. (2013) Candida albicans pathogenicity mechanisms. Virulence, 4(2), 119-128. http://dx.doi.org/10.4161/viru.22913

Borman A. M., Szekely, A., \& Johnson, E. M. (2016) Comparative Pathogenicity of United Kingdom Isolates of the Emerging Pathogen Candida auris and Other Key Pathogenic Candida Species. Clinical Science and Epidemiology, 1(4), e00189-16. http://dx.doi.org/10.1128/mSphere.00189-16

Silva, S., Negri, M., Henriques, M., Oliveira, R., Williams, D. W., \& Azeredo, J. (2012) Candida glabrata, Candida parapsilosis and Candida tropicalis: biology, epidemiology, pathogenicity and antifungal resistance. FEMS Microbiol Rev, 36(2), 288-305. http://dx.doi.org/10.1111/j.1574-6976.2011.00278.x

Deorukhkar, S. C., Saini, S., \& Mathew, S. (2014) Virulence Factors Contributing to Pathogenicity of Candida tropicalis and Its Antifungal Susceptibility Profile. International Journal of Microbiology, 2014, 1-6. http://dx.doi.org/10.1155/2014/456878

Rasool, U., \& Hemalatha, S. (2017) Marine endophytic actinomycetes assisted synthesis of copper nanoparticles (CuNPs): Characterization and antibacterial efficacy against human pathogens. Material Letters, 194, 176-180. http://dx.doi.org/10.1016/j.matlet.2017.02.055

Dash, S. K., Chakraborty, S. P., Mandal, D., \& Roy, S. (2012) Isolation and Characterization of Multi Drug Resistant Uropathogenic Escherichia coli from Urine Sample of Urinary Tract Infected Patients. Int J Life Sci Pharm Res, 2(1), 2250-0480.

Ekwealor, A. P., Ugwu, M. C., Ezeobi, I., Amalukwe, G., Ugwu, B. C., Okezie, U., Stanley, C. \& Esimone, C. (2016) Antimicrobial Evaluation of Bacterial Isolates from Urine Specimen of Patients with Complaints of Urinary Tract 
Infections in Awka, Nigeria. International Journal of Microbiology, 2016, 1-7. http://dx.doi.org/10.1155/2016/9740273

Kaur, P., Thakur, R., \& Chaudhury, A. (2016) Biogenesis of copper nanoparticles using peel extract of Punica granatum and their antimicrobial activity against opportunistic pathogens. Green Chemistry Letters and Reviews, 9(1), 33-38. http://dx.doi.org/10.1080/17518253.2016.1141238

Reshamwala, S. M., \& Noronha, S. B. (2011) Biofilm formation in Escherichia coli cra mutants is impaired due to down-regulation of curli biosynthesis. Arch Microbiol, 193(10), 711-22. http://dx.doi.org/10.1007/s00203-011-0708-7

Maiti, S., Krishnan, D., Barman, G., Ghosh, S. K., \& Laha, J. K. (2014) Antimicrobial activities of silver nanoparticles synthesized from Lycopersicon esculentum extract. Journal of Analytical Science and Technology, 5(40), 1-7. http://dx.doi.org/10.1186/s40543-014-0040-3

Amiri, M., Etemadifar, Z., Daneshkazemi, A., \& Nateghi, M. (2017) Antimicrobial Effect of Copper Oxide Nanoparticles on Some Oral Bacteria and Candida Species. J Dent Biomater, 4(1), 347-352.

Usman, M. S., Zowalaty, M. E., Shameli, K., Zainuddin, N., Salama, M., \&

Ibrahim, N. A. (2013) Synthesis, characterization, and antimicrobial properties of copper nanoparticles. Int J Nanomedicine, 8, 4467-4479. http://dx.doi.org/10.2147/IJN.S50837

Soltani, H., Salouti, M., \& Shokri, R. (2018) The Antifungal Effect of Silver, Copper Nanoparticles, and Their Combination and in combination with Amphotericin B against Candida albicans In Vitro and in Animal Model. Qom Univ Med Sci J, 11(12), 17-24.

Akther, T, Khan MS, Hemalatha S (2018) A facile and rapid method for green synthesis of myco nanoparticles using endophytic fungi. Int. J. Nano. Dimens. $9(4), 435-441$

Vazquez-Munoz, R., Avalos-Borja, M., \& Castro-Longoria, E. (2014) Ultrastructural Analysis of Candida albicans When Exposed to Silver $\begin{array}{lllll}\text { Nanoparticles. PloS } & \text { ONE, } & \text { 9(10), } & \text { e8876. }\end{array}$ http://dx.doi.org/10.1371/journal.pone.0108876

Yoon, K. Y., Hoon, B. J., Park, J. H., \& Hwang, J. (2007) Susceptibility constants of Escherichia coli and Bacillus subtilis to silver and copper nanoparticles. Sci Total Environ., 373(2-3), 572-5. http://dx.doi.org/10.1016/j.scitotenv.2006.11.007

de Castro, R. D., de Souza, T. M., Bezerra, L. M., Ferreira, G. L., Costa, E. M. \& Cavalcanti, A. L. (2015) Antifungal activity and mode of action of thymol and its synergism with nystatin against Candida species involved with infections in the oral cavity: an in vitro study. BMC Complementary and Alternative Medicine, 15(417), 1-9. http://dx.doi.org/10.1186/s12906-015-0947-2

Performance standards for antimicrobial disk susceptibility tests, M100S, 27th Ed., CLSI 2017, 37.

Uppuluri, P., Pierce C. G., \& López-Ribot, J. L. (2009) Candida albicans Biofilm Formation and its Clinical Consequences. Future Microbiol, 4: 1235-1237. http://dx.doi.org/10.2217/fmb.09.85

Bruzual, I., Riggle, P., Hadley, S., \& Kumamoto, C. A. (2007) Biofilm formation by fluconazole-resistant Candida albicans strains is inhibited by fluconazole. Journal of Antimicrobial Chemotherapy, 59(3), 441-450 https//dx.doi.org/10.1093/jac/dk1521

Rahimi, G., Khodavandi, A., \& Yaghob, R. (2016) Antimycotic Effect of Copper Oxide Nanoparticles on Candida albicans Biofilm. J. Micro \& Nano Biomed, 1(1): 7-12. http://dx.doi.org/10.15412/J.MNB.05010102

Yu, Q., Li, J., Zhang, Y., Wang, Y., Liu, L., \& Li, M. (2016) Inhibition of gold nanoparticles (AuNPs) on pathogenic biofilm formation and invasion to host cells. Sci. Rep, 6, 26667. doi: http://dx.doi.org/10.1038/srep26667

Akther T, Hemalatha S (2019) Mycosilver Nanoparticles: Synthesis, Characterization and its Efficacy against Plant Pathogenic Fungi. BioNanoSci.https://doi.org/10.1007/s12668-019-0607-y 